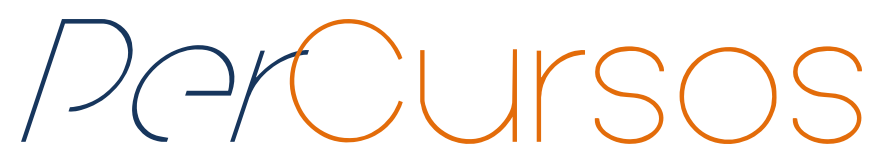

\title{
Aprender pesquisando, ensinar aprendendo: percursos formativos que reinventam práticas e saberes docentes
}

\section{Resumo}

As considerações deste artigo são resultado de um deslocamento proveniente da atividade reflexiva fundamentada em duas dimensões intercomunicantes e fundantes: a prática docente no Ensino Básico e as pesquisas acadêmicas no Mestrado Profissional de Ensino de História (ProfHistória). Apresentaremos e analisaremos os pressupostos teóricos do campo da Educação Histórica que respaldam nossa problemática investigativa. Para tal, abordaremos: a consciência histórica como forma de apropriação e significação do passado que se configura como um importante referencial nas ações e práticas dos indivíduos; os modelos de progressão do raciocínio dos estudantes; e o conceito de literacia histórica. Posteriormente, aprofundaremos nossa reflexão sobre os conceitos substantivos e meta-históricos, considerando-os elementos estruturantes da matriz disciplinar da História.

Palavras-chave: Educação Histórica. Aprendizagem Histórica. Consciência Histórica. Literacia Histórica. Conceitos Históricos.

\author{
Hugo Alexandre de Araújo \\ Mestrando Profissional em \\ Ensino de História (ProfHistória) \\ pela Universidade Federal de \\ Pernambuco - UFPE. Professor \\ da Educação Básica da Prefeitura \\ Municipal de João Pessoa-PB. \\ Brasil \\ hugo.história@hotmail.com
}
Marta Margarida de Andrade Lima
Doutora em Educação pela
Universidade Estadual de
Campinas - UNICAMP.
Professora da Universidade
Federal Rural de Pernambuco -
UFRPE.
Brasil

martamargarida.lima@gmail.com

\section{Para citar este artigo:}

ARAÚJO, Hugo Alexandre de; LIMA, Marta Margarida de Andrade. Aprender pesquisando, ensinar aprendendo: percursos formativos que reinventam práticas e saberes docentes. Revista PerCursos, Florianópolis, v. 18, n.38, p. 63 - 86, set./dez. 2017.

\section{DOI: $10.5965 / 1984724618382017063$}

http://dx.doi.org/10.5965/1984724618382017063 


\title{
To learn researching, to teach learning: formative paths which reinvent teaching practices and knowledge
}

\begin{abstract}
The considerations which configure the study object of this article are the outcome of a displacement from reflective activity based on two intercommunicating and foundational dimensions: the primary education teaching practice and the academic researches from the so called Program in Professional Master's Degree of History Teaching (ProfHistory). We introduce and analyze the theoretical assumptions of the Historical Education field that supports our research problematic. As a way to achieve the foregoing, we approach "historical consciousness" as a form of appropriation and meaning of the past that represents an important reference in the individuals actions and practices; The models of student reasoning progression; And the concept of historical literacy. Posteriorly, we probe our reflection on the substantive and metahistorical concepts, considering them as structural elements of the disciplinary matrix of History.
\end{abstract}

Keywords: Historical Education. Historical Learning. Historical Consciousness. Historical Literacy. Historical Concept. 


\section{Prática escolar, campo acadêmico e ressignificações: notas introdutórias}

A inserção no universo acadêmico e, posteriormente, a iniciação na docência no Ensino Básico proporcionam uma ebulição de sonhos. São significativas experiências, gigantescas explosões de ideias e utopias. A intersecção entre os campos das experiências universitária e profissional nos transporta, subitamente, para uma encruzilhada conflitante entre os saberes eruditos, as práticas escolares e as motivações pessoais. Assim, neste artigo, intencionamos trabalhar os diferentes trajetos percorridos a partir de uma intensa atividade reflexiva entre uma década de prática docente no Ensino Básico e as pesquisas no campo acadêmico proporcionadas pelo Mestrado Profissional em Ensino História (ProfHistória - UFPE). Nosso objetivo configura-se em apresentar os contributos teóricos que embasam nossa pesquisa e nos movimentam a pensar uma contribuição para a constante "reinvenção" do ensinar e aprender História, o que vem ensejando um olhar mais atento para as dificuldades que os alunos têm demostrado nas aulas de História, nos aguçando a investigar situações de aprendizagens históricas em contextos concretos, a partir dos pressupostos da Educação Histórica (ASHBY, 2006; BARCA, 2001, 2007, 2009, 2011 2012; COOPER, 2006; LEE, 2006, 2011).

A reinserção no campo acadêmico através do Mestrado Profissional tem nos possibilitado problematizar algumas ideias referentes à prática docente, sobretudo, quanto ao aprendizado dos estudantes. Denúncias quanto ao pouco conhecimento histórico demonstrado pelos discentes sobre fatos consolidados e quase sempre, cristalizados ao longo do tempo, além da apatia generalizada nas aulas, somam-se à percepção da dificuldade das crianças e dos adolescentes em compreenderem que o saber histórico é um conhecimento em construção. Refletir sobre tais aspectos é um movimento de ressignificação dos lugares que ocupam os professores no processo de ensino-aprendizagem da História.

É nesta perspectiva que as abordagens suscitadas pelas publicações do filósofo da História Jörn Rüsen e por pesquisadoras e pesquisadores ingleses, portugueses e brasileiros acerca da Educação Histórica foram tomadas como aportes teóricometodológicas da nossa pesquisa. Tal perspectiva possibilita pensar o ensino dos saberes 
históricos escolares a partir das relações entre a natureza do conhecimento histórico, os processos de ensino-aprendizagem e as orientações na vida prática.

Nosso ponto de partida foram as considerações de Jörn Rüsen (2011), que fundamenta suas proposições na necessidade de orientação temporal intrínseca aos seres humanos, em que a consciência histórica torna-se parte da ferramenta mental dos sujeitos e é utilizada como orientação no cotidiano pessoal e social. Para Rüsen, a ciência da História e sua "matriz disciplinar" fornecem aos sujeitos a possibilidade de agir intencionalmente a partir da orientação temporal histórica e da formação de suas identidades.

Quanto às pesquisas sobre a natureza do conhecimento histórico e sua relação com o Ensino de História, Peter Lee (2006), pesquisador inglês, liderou o Projeto CHATA (Concepts of History and Teaching Approaches - "Conceitos de História e Abordagens de Ensino"), investigando a compreensão dos alunos sobre a natureza e o status de diferentes tipos de afirmações históricas. Lee evidencia duas preocupações centrais nas pesquisas sobre Educação Histórica no Reino Unido: uma quanto ao significado e a como desenvolver a compreensão dos alunos na disciplina de História, outra, quanto àquilo que os alunos deveriam saber sobre o passado no final dos seus cursos escolares. Operando com os conceitos e as categorias da ciência de referência, forneceu um quadro detalhado dos tipos de ideias sobre história que os alunos conseguem reter. Ao longo de seus trabalhos investigativos, concluiu que alguns alunos foram capazes de trazer uma compreensão histórica sofisticada. Lembra-nos de algumas exigências para a disposição de "pensar historicamente", como em considerar a história um "compromisso de indagação" com suas marcas próprias de identificação, possuindo ideias características organizadas e um vocabulário de expressões.

Ao nos apropriarmos desses dois referenciais teóricos, destacamos que, embora seja possível estabelecermos um diálogo entre os dois autores, é necessário pontuar suas diferentes perspectivas (FREITAS, 2014).

Para Lee, a história como uma ciência fundamentada no método crítico deve ter também o seu ensino pautado em especificidades e metodologias próprias, ou seja, a 
produção do conhecimento histórico deve ganhar centralidade nas abordagens dos professores em sala de aula. Não que o objetivo da escola seja formar mini historiadores, mas que os alunos sejam mobilizados a construírem suas narrativas históricas a partir dos elementos estruturantes do saber de referência. Por conseguinte, "na prática, aprender história é fazer questionamentos às fontes, validar seus argumentos e evitar anacronismo, operações possíveis com a aquisição de conceitos e procedimentos relacionados aos termos tempo, mudança, compreensão, causa e relato" (LEE, 2005, p. 32,41 apud FREITAS, 2014, p. 47).

Já as conclusões de Rüsen exploram o campo da didática da história a partir dos processos de formação da consciência histórica. As circunstâncias e tomadas de decisões da vida prática levam os sujeitos a operarem três atos do pensamento: experimentar o passado, interpretar o passado como presente e orientar-se no presente visando o futuro. O que leva Freitas (2014, p. 52) a concluir que

[...] Rüsen não busca tais imperativos - fornecedores da racionalidade/cientificidade da história -, originariamente, na ciência da história. A racionalidade da história é extraída da vida prática, ou seja, a razão de existir de uma ciência da história está fundamentada na estrutura do homem imaginada por Rüsen, constituído a partir das operações de experimentação, intepretação e orientação, isto é, a partir da consciência histórica.

Embora definam a aprendizagem histórica em diferentes abordagens, Peter Lee e Jörn Rüsen têm influenciado diversas investigações que problematizam o ensino de História. Nos estudos sobre cognição histórica em países lusófonos, por exemplo, a pesquisadora Isabel Barca (2012) desenvolve seus trabalhos a partir da tese de que é possível a construção de ideias históricas gradualmente mais sofisticadas pelos alunos. Suas investigações são ancoradas numa reflexão epistemológica do conhecimento histórico e das análises das ideias que os sujeitos manifestam acerca da História.

A partir de tais contributos teóricos, estruturamos nossa reflexão em duas seções. Na primeira parte, recortamos alguns dos pressupostos-chave que vêm norteando as 
pesquisas no campo da Educação Histórica. Abordarmos três elementos fundantes: a consciência histórica, dialogando com os escritos de Jörn Rüsen (2011); os modelos de progressão do raciocínio das crianças e dos adolescentes, apresentados pelas pesquisadoras Rosalyn Ashby (2006) e Isabel Barca (2001); e o conceito de literacia histórica, proposto por Peter Lee (2006).

No segundo momento, examinamos as especificidades da História como saber disciplinar alicerçado em conceitos específicos que Ihe dão forma. Recortamos duas categorias meta-históricas: evidência, entendida como meio que nos possibilita acessar o passado, indagando-o, e mudança, enquanto elemento de compreensão que estrutura a construção do conhecimento histórico. Intentamos, para tal, estabelecer pontes entre os escritos de R. Koselleck (1992, 2006) e as propostas dos pesquisadores analisados.

\section{Educação histórica: alguns pressupostos}

As considerações que se seguem são resultado de um deslocamento proveniente da atividade reflexiva fundamentada em duas dimensões intercomunicantes e fundantes: a prática docente no Ensino Básico e as pesquisas sobre ensino de História no campo acadêmico. Tal movimento possibilitou situar os debates historiográficos e as querelas teóricas sobre as especificidades do conhecimento histórico nas discussões referentes aos processos de ensino e aprendizagem, sobretudo, dos saberes históricos escolares.

Por este ângulo, como campo de pesquisa profícuo, a Educação histórica tem possibilitado ampliar o diálogo entre teorias e práticas de ensino, nutrindo-se dos princípios da aprendizagem situada, dos saberes históricos escolares e sua epistemologia, dos procedimentos metodológicos, das concepções e práticas dos agentes educativos (BARCA, 2012). Tal perspectiva emerge da tese de que é possível a construção de ideias históricas gradualmente mais sofisticadas pelos estudantes, no que respeita à natureza do conhecimento histórico. Contrapondo, assim, nos dizeres de Isabel Barca (2001, p.13), 
Piaget e Bloom tendo por base as características das ciências "exatas" como a Física e Matemática. Estes pressupostos generalistas conduziram alguns autores a concluírem que a História era demasiado complexa para ser estudada por alunos com idades mentais inferiores a 16 anos.

Contrária a tal enfoque, a Educação Histórica propõe pensar o ensino a partir das relações entre as especificidades do saber histórico e os processos de ensino que mobilizem aprendizagens significativas. Traça-se, desta forma, como objetivo, construir uma ponte gradual entre o que os alunos aprendem e o que os historiadores e filósofos da ciência de referência pensam e produzem. Logo, a pesquisa e as ações visam criar, implementar e analisar situações de aprendizagem em contextos concretos que potencializem o desenvolvimento, pelos discentes, de ideias históricas do passado mais fortes, ou seja, significantes em seus percursos diários. ${ }^{1}$

Duas preocupações são centrais nos estudos realizados no Reino Unido: uma, quanto ao significado e desenvolvimento da compreensão dos alunos na disciplina História. E outra, quanto àquilo que os estudantes deveriam saber sobre o passado ao final dos seus cursos escolares. Assim, busca-se compreender, entre outras problemáticas de pesquisa, como as crianças e jovens elaboram suas ideias sobre história e como mobilizam os usos do passado em seus cotidianos, bem como, quais os processos cognitivos que promovem a construção do pensamento histórico, ou seja, quais os elementos de que os sujeitos se apropriam para construírem suas percepções do passado. E, além disso, como a história favorece pensar e interpretar a existência humana que respondam as carências de orientação no tempo? (RÜSEN, 2011).

\subsection{Consciência histórica e as orientações na vida prática}

O conceito de consciência histórica constitui um dos objetos centrais no campo da Educação Histórica permitindo um melhor entendimento das ideias de jovens acerca dos

\footnotetext{
${ }^{1}$ Isabel Barca (2001, 2009, 2012) utiliza a expressão "ideia histórica mais forte" com o sentido de uma afirmação histórica que não se apresenta de forma caótica e fragmentada. Ao contrário, a define como um olhar para o passado contextualizado e aberto a múltiplas perspectivas, em que os estudantes passam a "utilizá-lo" para uma análise mais crítica do mundo atual.
} 
usos da história em seu cotidiano. Todavia, a polissemia do termo mobiliza intensos debates acadêmicos. Luís Fernando Cerri (2011), por exemplo, propõe uma análise da consciência histórica em três vieses analíticos: o que é a consciência histórica? Há uma conscientização histórica? E quais as consequências dessas abordagens para a prática do profissional de história?

Segundo Cerri, uma primeira abordagem, a partir dos estudos de Hans-Georg Gadamer e Philipe Ariès ${ }^{2}$, considera a consciência histórica um estágio ao qual se chega através de um processo de modernização. Sendo, portanto, privilégio do homem moderno a tomada da consciência da história, fazendo-o perceber quais são os seus condicionamentos ao longo do tempo. Nesta perspectiva conceitual está implícito que há uma "inconsciência histórica" dos povos não modernizados. Gadamer, inclusive, indica a existência do "senso histórico" em que as massas dos países periféricos carentes dos “progressos da modernidade” apenas se apropriam do passado, mas sem julgá-lo.

Diferentes são as perspectivas dos trabalhos de Jörn Rüsen e Agnes Heller ao conceberem a historicidade como algo intrínseco à própria vida humana prática. Ou seja, a "história" é todo o conhecimento produzido pelos indivíduos e coletividades que significam o tempo, sendo por isso inerente às próprias estruturas do pensamento humano. Por conseguinte, de forma global, todos os seres humanos lidam com o passado; possuem, assim, consciência histórica (CERRI, 2011).

Neste caminho, Rüsen (2011, p.36) afirma que,

[...] a consciência histórica não pode ser meramente equacionada como simples conhecimento do passado. A consciência histórica dá estrutura ao conhecimento histórico como meio de entender o tempo presente e antecipar o futuro. Ela é uma combinação complexa que contém a apreensão do passado regulado pela necessidade de entender 0 presente e presumir o futuro.

\footnotetext{
${ }^{2}$ No texto "A história marxista e a história conservadora" (1989), Phillipe Ariès fala em tomada de consciência da história no sentido de que o indivíduo passa a aperceber-se da sua condição de determinado pela história. Ariès se aproxima das colocações de Gadamar, ao considerar o desencadeamento da percepção da história como resultado dos processos de modernização (CERRI, 2011).
} 
Portanto, "ter consciência histórica” não é adotar um paradigma historiográfico, nem muito menos “dominar” e defender uma narrativa substantiva da História. Tal noção dialoga mais com o conjunto coerente de operações mentais que definem a especificidade do pensar historicamente e suas funções na existência humana.

Rüsen propõe um instrumento ideal-típico para a análise e a interpretação de processos concretos do aprendizado histórico em quatro dimensões: tradicional, exemplar, crítica e genética. Segundo ele, a aprendizagem tradicional processa as experiências temporais como condutoras das ações, sendo aceitas e reconstruídas como orientações estabilizadoras da vida prática. Já a aprendizagem exemplar, para além da tradição, estabelece o espaço de experiência como regra geral para o agir no horizonte de expectativa. Ou seja, consolida modelos históricos a serem seguidos. O que difere do aprendizado crítico, em que as experiências temporais serão empregadas de modo que anulem ou refaçam os modelos impostos a partir de uma revisão dos interesses intersubjetivos. Por fim, a aprendizagem genética, na qual

[...] os sujeitos aprendem, na produtiva aquisição da experiência histórica, a considerar sua própria autorrelação como dinâmica e temporal. Eles compreendem sua identidade como "desenvolvimento" ou como "formação", e ao mesmo tempo, com isso, aprendem a orientar temporalmente sua própria vida prática de tal forma que possam empregar produtivamente a assimetria característica entre experiência do passado e expectativa do futuro. (RÜSEN, 2011, p. 46)

Como atividade reflexiva, é importante salientarmos que as apropriações teóricas de Rüsen nos mobilizam a dialogar com outras compreensões do conhecimento histórico, possibilitando, inclusive, inferirmos que há em seus escritos uma centralidade e supervalorização damatriz disciplinar acadêmica, na qual a racionalidade histórica garantiria a legitimidade aos historiadores para considerar e privilegiar suas pesquisas e escritos como "[...] meios específicos de realizar aquelas operações da consciência que proporcionaram aos seres humanos segurança e autopersistência [...]” (RÜSEN, 2011, p. 39). Além disso, há a dificuldade de se considerar a tipologia proposta das fases e níveis 
do desenvolvimento da consciência histórica em sua ordem linear: da tradicional à genética.

Embora as discussões teóricas de Rüsen necessitem de tais reservas, elencamos alguns contributos possíveis para pensar o aprendizado histórico a partir de suas proposições. Dentre eles: o desenvolvimento processual de uma competência narrativa aberta à orientação temporal da vida prática sobre a experiência histórica; a necessidade de atrelar o aprendizado à subjetividade do aprendiz; e a possibilidade de colocar em questão a construção das identidades históricas abertas à comunicação racionalargumentativa (RÜSEN, 2011).

Ao dialogar com Hayden White e Paul Ricoeur, Rüsen define a narração histórica como um procedimento mental básico que dá sentido ao passado com a finalidade de direcionar o tempo presente e pensar as ações no futuro. A competência narrativa seria o processo no qual se abrem os olhos para a história, ou seja, para a presença perceptível do passado. Os seres humanos ao narrarem sobre si e sobre os "outros" se percebem como sujeitos detentores de historicidade (RÜSEN, 2011).

Esta relação com o passado torna-se aprendizado histórico quando se relaciona à subjetividade dos receptores, aos problemas e às situações de orientação que influem em suas significações. No campo educacional, as impressões do passado que os alunos carregam consigo são fortemente marcadas por seus percursos diários, sendo, portanto, fundamental percebê-las e, sobretudo, considerá-las importantes no processo de complexificação do pensar historicamente.

Isto requer, também, propor situações didático-pedagógicas que mobilizem diálogos intersubjetivos em que as formas e usos dos pensamentos históricos não devem partir do poder e da dominação e sim dos argumentos racionais.

Por tal perspectiva, Peter Lee (SILVA, 2012) considera as contribuições dos trabalhos de Rüsen para propor uma visão de história e de educação histórica a partir de uma abordagem do passado com problemas de orientação e identidade. Segundo ele, "a natureza histórica como uma forma de ver o mundo (e que pode transformar como os alunos veem a si mesmos no tempo e como concebem a possibilidade e o status do 
conhecimento do passado) é, claro, central para a educação histórica" (LEE, 2012 p. 223 apud SILVA, 2012).

Portanto, o ensino de História deve trabalhar com aprendizagens meta-cognitivas que promovam a sofisticação da consciência histórica dos jovens, permitindo-lhes construírem uma sociedade aberta, crítica e dialógica. Ensejando, portanto, a disposição de se perceberem como sujeitos históricos imersos nas dimensões temporais, que compreendam a construção do conhecimento histórico e que reflitam sobre seus sentimentos de pertença pautando, consequentemente, suas relações humanas em dois conceitos fundamentais: a empatia e a alteridade.

Neste ponto, Isabel Barca (2007) alerta-nos para a necessidade de delimitação conceitual acerca da consciência histórica e da identidade social. Explica-nos que os sentimentos de pertença e identidade social constroem-se no decurso das vivências diárias. Apesar de diversos agentes apresentarem-se como constituintes de tais sentimentos (família, Estado, mídia, entre outros), a instituição escolar é um espaço privilegiado para (re) orientar e/ou aprofundar as identidades sociais, sobretudo, na aprendizagem disciplinar da História.

No que se referemà relação entre os sentimentos de pertença e o saber histórico escolar, os seus currículos, ao selecionarem os conteúdos, as perspectivas historiográficas, as metodologias, os princípios educativos, as efemérides, as memórias e os esquecimentos, lançam-nos nos embates em torno da categoria identidade(s). A proposta da Educação Histórica reitera que o ensino de história “[...] contribua para a mobilização de identidades na construção de uma consciência histórica adequada às complexidades da sociedade neste início de século, e no contexto de uma sociedade que se deseja aberta e dialogante [...]" (BARCA, 2007, p. 116).

Para a consolidação deste percurso formativo, uma aprendizagem histórica “sofisticada" requer múltiplas estratégias didáticas que viabilizem aos estudantes a disposição para se apropriarem de competências historiográficas, favorecendo, deste modo, um pensamento histórico em perspectiva. Ou seja, um ensino que trabalhe a percepção de que o conhecimento histórico é construído, onde o passado não é dado e 
que o mais importante não seria a apreensão do conjunto de informações históricas baseado no "que é", mas sim no "como e por que é".

Esta afirmação nos desloca para as reflexões de Mario Carretero (2010) sobre os princípios e as finalidades do saber histórico escolar. Afinal, por que, para quem e para que se ensina História na escola? Carretero sustenta a tese da emergência desta disciplina escolar, no século XIX, a partir de duas finalidades educacionais paradoxais: a llustração e o saber crítico, em uma via, e o Romantismo e a perspectiva nacionalista, em outra. Ou seja, o conhecimento histórico está inserido nas disputas curriculares que lhe dão sentido como: a) meio de consolidar os sentimentos de pertença dos cidadãos aos Estados nação, fixando uma narrativa única do passado e; b) caminho para desenvolver um olhar crítico da realidade através do saber histórico, valorizando a autonomia do pensar em perspectiva.

Propor como objetivos das aulas de História, nas escolas da Educação Básica, uma aprendizagem ativa em que os processos de ensino sejam direcionados aos estudantes com a finalidade de estarem à disposição da criticidade, da desnaturalização dos usos do passado, da compreensão do próprio fazer historiográfico e seus impactos na vida prática é defender um projeto político pedagógico cujos fins convergem para a formação de indivíduos conscientes de sua historicidade.

Nesta acepção, as disputas curriculares alusivas aos saberes históricos escolares quanto aos seus princípios ilustrado/crítico e romântico/nacionalista, apontados por Mario Carretero, são delineadas. Ao invés de se valorizar uma narrativa positiva, única e restrita do passado, se propõe compreendê-lo de forma complexa, distinguindo as diferentes temporalidades, compreendendo a causalidade histórica, aproximando-se das metodologias do saber de referência e relacionando-o com o presente e o futuro (CARRETERO, 2010).

Todavia, operar com diferentes referenciais teóricos exige-nos estar atentos aos limites das ideias e metodologias dos pesquisadores analisados. Desta maneira, é possível estabelecer um diálogo reflexivo que seja capaz de guiar nossas pesquisas, e posteriormente, propor intervenções didático-pedagógicas. Por conseguinte, passamos a 
assinalar alguns resultados de pesquisas vinculadas à Educação Histórica sobre como os estudantes elaboram ideias sobre história.

Antes, chamamos a atenção para os cuidados a serem tomados no trabalho com modelos de progressão de ideias. Toda e qualquer proposta de categorização do pensamento dos estudantes não deve incorrer em generalizações, nem a modelos rígidos do desenvolvimento das estruturas cognitivas. Cairíamos no equívoco de nos apropriarmos do pensamento de Piaget, concluindo, previamente, a impossibilidade das crianças e jovens de aprenderem ideias mais sofisticadas devido às suas imaturas estruturas biológicas. Apresentaremos, distintivamente, os modelos ideal-típicos como ferramentas para compreender de que maneiras os estudantes mobilizam os saberes na construção de suas explicações históricas e, a partir disto, pensar quais procedimentos didáticos podem se configurar como ferramentas significativas para mobilizar a disposição do pensar historicamente.

\subsection{Progressão das ideias históricas dos estudantes}

O Projeto CHATA examinou as estratégias discursivas dos alunos em suas arguições históricas, bem como o seu entendimento da relação entre proposições históricas e as evidências sobre as quais repousam. Rosalyn Ashby (2006), ao discutir os resultados de pesquisa feitos com 320 crianças britânicas de três escolas primárias e seis escolas secundárias, concluiu que alguns alunos foram capazes de trazer uma compreensão sofisticada de evidência, em relação aos demais. A pesquisadora elencou cinco estratégias dos alunos para justificar suas respostas: i) livros e especialistas; ii) relíquias e registros; iii) credibilidade de variadas fontes; iv) questionamento da afirmação (inferência a partir das fontes); v) plausibilidade. Diante dos resultados, chegou ao entendimento que os alunos mais jovens tendem a contar com a autoridade dos livros e especialistas, mais do que os alunos mais velhos, ainda que permaneça um número de alunos mais velhos que também o fazem. A pesquisa trouxe à tona o salto conceitual que os alunos precisam fazer, a partir da compreensão das fontes como testemunhos, para trabalhar o conceito de evidência. Neste sentido, a investigação histórica deve ser um 
elemento central no ensino de História, potencializando, assim, uma maior aproximação e significação dos estudantes pelas considerações históricas.

Ashby afirma que somente um "saber como" pode oferecer o "direito de certeza". Neste caminho, as diferentes questões exigem diferentes procedimentos. À vista disso,

[...] o ensino de História necessita prestar atenção à natureza das afirmações históricas conjuntamente aos trabalhos que os alunos se ocupam com as fontes. Se os alunos devem desenvolver um conceito de evidência, eles necessitarão compreender a relação entre as evidências e as fontes históricas (compreendidas a partir de um conceito de que foi a sociedade quem as produziu) e as informações sobre o passado que elas apoiam. (ASHBY, 2006, p. 155)

A autora apresenta o "pensar de forma mais sofisticada" como um dos objetivos da aprendizagem histórica. Propõe a categorização das ideias dos adolescentes acerca da empatia histórica da seguinte maneira: “o passado opaco" (a experiência do passado inteligível); "estereótipos generalizados" (as ações e instituições do passado são compreendidas por uma referência a uma descrição convencional de intenções e valores); "empatia derivada do cotidiano" (o passado é interpretado a partir do tempo presente, não havendo distinção entre as diferentes temporalidades); "empatia histórica restrita” (a compreensão histórica é resultado das inferênciasas evidências sobre uma situação histórica específica); "empatia histórica contextualizada” (quando um conjunto vasto de evidências fundamenta as explicações históricas).

Inquirindo, similarmente, sobre a análise das ideias que os sujeitos manifestam em e acerca da História, a pesquisadora Isabel Barca (2001) sistematiza os princípios e as estratégias da aprendizagem histórica. Trabalhando com narrativas de jovens portugueses dos 6 aos 14 anos, Barca explora a noção de provisoriedade da explicação histórica. Categoriza as respostas dos estudantes em cinco níveis conceituais: "estória” (centra-se na informação descritiva ou explicativa restrita); "explicação correta" (apresenta o nível do senso comum sendo valorizado o testemunho direto); "quanto mais fatores melhor" (distinguem fontes e explicações sem confundir os conceitos de 
explicaçãoe evidência); "uma explicação consensual” (indicam posturas de objetividade na qual as evidências são instrumentos de verificação da verdade); "perspectiva" (as evidências históricas confirmam ou refutam a verdade histórica, o que indica a noção de verossimilhança).

Desta maneira, sequencialmente, da mais genérica a mais complexa, identifica os níveis de explicações históricas que se caracterizam pelo seu modo descritivo e restritivo, centrado na informação crua; enquanto outras, pelo nível do senso comum, em que há uma sobrevalorização das testemunhas diretas; sofisticando-se, posteriormente, pela soma de fontes ou interligação de fatos como condição básica das afirmações históricas; em seguida, pelo nível do entendimento que as fontes (evidências) são encaradas como verificações da verdade; e por fim, um estágio em que as narrativas são elaboradas a partir das evidências históricas, entendidas como instrumento de confirmação ou refutação de argumentos. Neste último estágio, os estudantes compreendem que a história é resultado de operações mentais e que são sempre respostas de determinados pontos de vistas.

Como mencionado anteriormente, a apropriação de modelos ideal-típicos dos raciocínios históricos das crianças e jovens deve ser manejada com cautela, evitando, por exemplo, atrelar a ideia de progresso contínuo ao desenvolvimento cognitivo, ou seja, generalizar a evolução do pensamento mais simples a mais complexos. As conclusões das pesquisas sobre a aprendizagem histórica de crianças e adolescentes explicitam que tanto em diferentes idades há diferentes níveis de compreensão, como em alunos da mesma faixa etária, conforme identificamos nas análises de Hilary Cooper (2006) sobre os processos de investigação histórica através da compreensão do conceito de tempo e dos usos das fontes históricas pelas crianças de três a oito anos. Com base nas narrativas dos alunos de quatro anos sobre continuidade e mudança ao longo do tempo, Cooper identificou alguns raciocínios que se limitavam a perceber apenas os aspectos do "novo" e do "velho" a partir das inferências das fontes históricas, enquanto que outros buscaram explicar o porquê das pessoas serem diferentes. Isto revela, para a pesquisadora, um pensamento mais elaborado. 
Assim, também, conclui Barca (2001, p. 32): “nota-se que, neste estudo, alguns alunos mais novos apresentaram um pensamento claramente explicativo e alguns mais velhos mostraram raciocinar ao nível da simples descrição." Deste modo, os estágios de desenvolvimento mental não são invariantes. Há crianças de sete anos com um pensamento histórico ao nível dos adolescentes de dezesseis anos e vice-versa. Portanto, tais instrumentos de análise são ferramentas para propor estratégias didáticopedagógicas que potencializam a sofisticação do pensar historicamente, ou seja, que promovam situações favoráveis aos alunos para estarem dispostos a lerem o mundo com a historicidade nos olhos. Uma condição que requer um "letramento histórico", ou melhor, uma utilização das competências específicas do saber histórico para a construção de narrativas abertas à criticidade e a contrapontos que garantam a continuidade da reinterpretação da história.

\subsection{Literacia histórica e o olhar na historicidade}

Adentramos, por conseguinte, nas reflexões sobre o conceito literacia histórica, propostas por Peter Lee (2006), em que a compreensão da disciplina da história com suas especificidades e a utilização de uma estrutura utilizável do passado caracterizam a complexificação da aprendizagem histórica. Para o pesquisador, os estudantes desenvolvem ideias históricas gradualmente mais sofisticadas quando se aproximam de uma atitude investigativa. Isto é, quando os processos de ensino e aprendizagem tornamse ativos mediante as reflexões epistemológicas próprias do conhecimento histórico. É, em outras palavras, o desafio de aproximar os jovens das especificidades da produção do conhecimento histórico, possibilitando a percepção de "como" se constrói o discurso histórico.

Entretanto, a compreensão histórica configura-se como aprendizagem na medida em que os alunos não apenas organizam e explicam o passado, mas o utilizam para as orientações da vida prática. A história, assim concebida, estimula os jovens estudantes a pensarem e refletirem sobre a experiência temporal, guiando-os em suas vivências cotidianas. 
A intencionalidade pedagógica reside em fornecer condições para que os alunos possam ultrapassar o ideal romântico-nacionalista do passado fixo e indiscutível, alcançando, assim, o princípio iluminista-crítico em que a história em perspectiva é compreendida como uma construção.

Entre algumas exigências para a literacia histórica está a percepção dos alunos sobre o conhecimento histórico, de que ele exige um "compromisso de indagação", e que este saber possui ideias e conceitos característicos. Para Lee, demanda também os usos das evidências na formulação das explicações históricas e um entendimento de que estas podem ser contingentes ou condicionadas pelas crenças, valores e intenções dos agentes envolvidos em suas formulações (LEE, 2006).

A especificidade do saber histórico requer o domínio de um quadro conceitual amplo. Tais conceitos são chaves de significação das realidades temporais - passado, presente e futuro. O campo de pesquisa da Educação Histórica sugere que a mudança positiva no pensamento dos alunos se dá quando os mesmos passam a operar com categorias específicas deste campo de saber.

A mobilização de conceitos e categorias adquire centralidade no campo da Educação Histórica e na pesquisa que desenvolvemos no ProfHistória. Assim posto, passamos, na próxima seção, a apresentar a possibilidade de utilizá-los como instrumentos mobilizadores de aprendizagens ativas e significantes.

\section{Conceitos meta-históricos e aprendizagem histórica}

Os significados do que é "aprender História" diante do conceito de literacia histórica demandam criar ambientes e estratégias que forneçam condições aos alunos para exercitarem os procedimentos e elementos característicos da produção do conhecimento histórico, permitindo-lhes, consequentemente, estruturarem seus pensamentos de forma mais autônoma e participativa. O que nos exige, primeiramente, indagar: como se constrói o discurso histórico? E quais os elementos e as metodologias que caracterizam a História como disciplina? Uma resposta possível é navegarmos na história dos conceitos. 
É através dos conceitos que os seres humanos lidam com o real, atribuem sentidos e significados às coisas, nomeiam os fatos, constroem saberes, se identificam e relacionam-se uns com os outros. "Sem conceitos comuns não pode haver sociedade e, sobretudo, não pode haver unidade e ação política” (KOSELLECK, 2006, p. 98). Os conceitos, diferentemente das palavras, exigem certo nível de teorização e abstração; são resultados de associações; possuem um sentido mínimo comum; atrelam-se a referenciais históricos; são socialmente e politicamente relevantes; não são meros fenômenos linguísticos, mas, também, construtores da realidade (KOSELLECK, 1992).

A matriz disciplinar da História, dentre a multiplicidade de paradigmas historiográficos, fundamenta-se em conceitos específicos que dão forma ao saber histórico. R. Koselleck (1992) aponta que, ao mergulhar no passado, os historiadores são conduzidos por perguntas, desejos, anseios. Tais disposições condicionam a transformação dos vestígios conservados até o presente em testemunhos da história que se deseja aprender. Assim, os historiadores se relacionam com os fatos em duas dimensões: uma, com conceitos ligados as fontes, e outra, em categorias científicas do conhecimento capazes de fundamentar a possibilidade de uma narrativa histórica.

Neste sentido, podemos entender a proposta de Peter Lee de operacionalizar suas pesquisas por meio de duas ordens de conceitos: os substantivos e os de "segunda ordem”. Os primeiros são o que poderíamos chamar de substratos da História. Nomeiam e atribuem sentido aos acontecimentos, às relações humanas e sociais, ao imaginário e aos conjuntos de representações; são fatos linguísticos que permitem pensar a realidade historicamente (KOSELLECK, 1992). Já os de “segunda ordem”, ou meta-históricos, dão a especificidade da História. São constituidores da operação historiográfica, ou seja, articulam-se aos conceitos substantivos para dar a "fisionomia" desta ciência de referência. Vejamos, por exemplo: ao darem ordem temporal ao passado, os historiadores explicam o porquê dos eventos e processos; logo, mobilizam as categorias de tempo, explicação e causalidade. Também, em seu ofício, escrevem sobre o passado baseado em vestígios disponíveis, manipulando dois outros conceitos meta-históricos: evidência e narração. 
São justamente as propostas e estratégias de dar centralidade aos conceitos metahistóricos nas aulas de História que têm possibilitado o campo da Educação Histórica pensar em como favorecer meios para que o aluno sofistique seu quadro conceitual e, assim, o seu pensar. A questão primordial está em como relacionar o conhecimento de uma história substantiva com as ideias de segunda ordem, que oportunizem os jovens a “usarem" esse conhecimento de forma crítica e "útil” em seus percursos diários. Ou seja,

Para os jovens darem sentidos genuínos ao passado, e entende-lo numa relação com as suas próprias vidas, não basta aprenderem a reproduzir uma dada narrativa substantiva, com as suas descrições e explicações "completas" sobre os temas estipulados pelos conteúdos curriculares. É necessário que os jovens aprendam, sim, narrativas substantivas para a formação de um quadro de ideias válidas sobre o passado; mas é necessário que desenvolvam também, em simultâneo, ideias cada vez mais elaboradas sobre a História - idéias metahistóricas ou de "segunda ordem" - que lhes forneçam um aparato conceitual mais sofisticado, uma literacia mais avançada, em suma, um equipamento intelectual para uma ação mais sustentada e criativa. (BARCA, 2009, p. 60)

Entre os conceitos de segunda ordem elencados em nossa pesquisa no âmbito do ProfHistória, recortamos o de evidência, entendida como meio que nos possibilita acessar o passado, indagando-o, e de mudança, enquanto elemento de compreensão temporal que estrutura a construção do conhecimento histórico. Metaforicamente, as evidências são o esqueleto da História como disciplina. Concebê-las e problematizá-las como conjuntos de indícios fornecidos pelos vestígios do passado possibilita demarcar uma narrativa histórica de uma escrita ficcional. Seus usos dão, de certa maneira, uma racionalidade à investigação histórica.

No âmbito dos processos educacionais e das propostas defendidas até aqui, um movimento inicial é investigar como os alunos lidam com as evidências. Primeiramente, afirmamos ser um princípio fundamental, nas ciências da Educação, a compreensão dos conhecimentos tácitos dos jovens que, somente assim, nos possibilitará entender as situações concretas em que se desenvolvem os processos de ensino e aprendizagem. Para Carretero, por exemplo, “[...] dois elementos parecem ser importantes para a 
compreensão das Ciências Sociais e da História: de um lado, o conhecimento prévio do aluno e, de outro, as características específicas do conhecimento social e histórico que condicionarão, em grande parte, o seu aprendizado" (CARRETERO, 1997, p. 32).

Quando as ferramentas conceituais fazem sentido no mundo presente, podemos inferir que a aprendizagem histórica tornou-se significativa. O que nos obriga a perceber que os estudantes não vêm para as salas de aula de mãos vazias. Eles carregam consigo um conjunto de ideias nascidas das suas experiências. Possuem e defendem imagens do passado nutridas por suportes diversos, tais como as indústrias de entretenimento, as mídias sociais, entre outros. Olhar com sensibilidade e respeito para as ideias prévias das crianças e dos adolescentes permite aos professores mobilizarem tais saberes para ajudálos a avançar no processo de construção do conhecimento, no nosso caso, histórico.

O que Isabel Barca (2001) indica é que muitas das ideias tácitas dos alunos acerca da História apresentam-se de forma caótica, carregando frequentemente visões estereotipadas e preconceituosas. Por isso faz-se necessário mobilizar os estudantes para quebrar esses preconceitos cotidianos e desnaturalizar tais visões históricas. Para esta finalidade, construir uma imagem do passado a partir da compreensão e inferência das evidências é uma estratégia possível.

Encontramos no modelo de progressão proposto por R. Ashby (2006) uma pista de como os estudantes compreendem a categoria evidência. De acordo com a pesquisadora, a maioria dos alunos trata as evidências como informações que oferecem acesso direto ao passado, ou seja, são cópias fieis de uma realidade pretérita. Outros já demonstram entendê-las como testemunhos a serem avaliados quanto à sua veracidade, e poucos já possuem ideias mais elaboradas das evidências como "indícios" do passado que fundamentam ou refutam as afirmações históricas. O desafio está em sugerir aos alunos assumirem que a história é construída como conhecimento mediante o encontro de múltiplas fontes e, em consonância com as diversas problemáticas emergidas das questões socialmente vivas do presente. Portanto, conhecer o passado envolve realizar inferências sobre as fontes e, primordialmente, responder à questão-problema. "Se as fontes devem nos dizer sobre o passado, nós precisamos fazer perguntas sobre do que 
elas são feitas, quem as fez, por que, como foram usadas e o que significaram para as pessoas que as fizeram e as usaram?" (COOPER, 2006, p. 178).

A proposta demobilizaros alunos a "manipularem" criticamente as evidências, tornando-as estruturantes dos seus pensamentos, é uma possibilidade de fomentar dois outros aspectos: a imaginação e a empatia histórica. "Viajar" no tempo, imaginar como as pessoas viveram, indagar sobre as intenções dos sujeitos históricos, sugerir repostas, manusear os vestígios - são elementos que os aproximam da história. Favorecem, inclusive, um olhar mais próximo do "outro". Afinal, o ensino de História, e as outras dimensões da educação, não almejam respeito e igualdade numa perspectiva da alteridade? Em função disso,

\begin{abstract}
A atividade histórica pressupõe, pelo menos, a preocupação quanto à liberdade em assegurar o que a evidência nos leva a crer (para nós mesmo e para os outros); e também uma concepção de homem como um ser racional (como oposto da irracional). Isto pressupõe uma igualdade de tratamento e um respeito por pessoas como fontes de argumentos. Nestas circunstâncias, isto parece ser profundamente razoávelsem poderosos contra-argumentos para negar que estas mudanças no passado estão no curso da liberdade, igualmente no respeito pelas pessoas e no desenvolvimento da racionalidade da sociedade, como importância intrínseca para a história. (LEE, 2011, p. 26)
\end{abstract}

Intercomunicando com usos das evidências, nossa pesquisa investiga metodologias que mobilizem a compreensão dos estudantes da categoria mudança, percebida como um elemento estruturante do conhecimento histórico. Procedemos da perspectiva teórica da historicidade dos conceitos, dialogando com os escritos de Koselleck (2006).

Uma história dos conceitos é possível quando consideramos que todo fato linguístico articula-se a um contexto, sobre o qual também atua. Ou seja, em todo conceito há um emaranhado de textos e contextos operados em dois movimentos: sincrônico e diacrônico. A sincronia de um conceito remete à noção de que ele só pode ser pensado, falado e expressado enquanto tal uma única vez, por estar relacionado a uma situação concreta única. Entretanto, e paradoxalmente, todo conceito também é 
diacrônico, ou seja, carrega dentro dos seus conteúdos um mosaico de temporalidades. A diacronia e sincronia de um conceito alimentam-se. Logo, podemos pensar então, nas mudanças, permanências e simultaneidade desses signos linguísticos.

A sincronia e a diacronia dos conceitos são ferramentas analíticas que possibilitam a compreensão da mudança na história. Porém, cada paradigma historiográfico concebeu sentido e significado diversos a esta categoria. Desde as concepções de progresso social e científico, aos pesos das mudanças estruturais de longo prazo, até às transformações ao nível micro. Todavia, os escopos teóricos dos quais nos apropriamos para desenvolver nossa proposta de pesquisa residem nos usos e inferências das evidências para a compreensão de que os conceitos substantivos da História ${ }^{3}$ emergem de contextos concretos e passam por modificações ao longo do tempo, embora carreguem consigo diferentes textos.

\section{Possibilidades: traçados de uma conclusão}

As concepções de aprendizagem tomadas como referências nas proposições da Educação Histórica ampliam o diálogo entre os campos da experiência docente e acadêmica. Permitem um olhar diferente para as práticas e os lugares ocupados pelos sujeitos da aprendizagem nos processos de ensino. Colocam os princípios e as metodologias do ensino de história numa perspectiva crítica, desnaturalizando-os.

Neste sentido, investigar a consciência histórica como estrutura fundante do pensamento humano, podendo ser complexificada com as intencionalidades pedagógicas propostas nas aulas de história, é um movimento de "reinvenção" do fazer docente. Bem como, mobilizar os estudantes a inferir sobre os conceitos que dão forma e constroem o conhecimento histórico é garantir-lhes centralidade na produção de saberes significantes em seus percursos diários.

\footnotetext{
3 Selecionamos as concepções de "nação" e "nacionalismo" como substratos da História, o que vem nos permitindo fazer outro movimento investigativo: pensar de que maneira os jovens se situam enquanto sujeitos de identidades em contato com diferentes possibilidades de compreensão e apropriação desses conceitos explorados nas aulas de História, que embora não estejam mais centradas na legitimação da identidade nacional, abordam formas de nacionalismos, que via de regra, são trabalhadas a partir das imagens "de nós e dos outros" construídas, modificadas e/ou reiteradas historicamente.
} 
Finalizamos, assim, reafirmando a potencialidade do Profhistória na realização de trabalhos que persigam o perscrutar das práticas e dos saberes circulantes e mobilizados em salas de aulas. A formação docente continuada se revigora com a opção do Mestrado Profissional em Ensino de Historia. É, por conseguinte, um profícuo espaço de ressignificação dos profissionais da História, promovendo profundas reflexões sobre a construção do conhecimento histórico no espaço escolar através do exercício do fazer historiográfico, pensado a partir do método e do arcabouço desta ciência, em diálogo construtivo e ampliado com as situações de aprendizagem e com as múltiplas facetas constitutivas da escola, das suas diretrizes, finalidades e relações sociais.

\section{Referências}

ASHBY, Rosalyn. Desenvolvendo um conceito de evidência histórica: as ideias dos estudantes sobre testar afirmações factuais singulares. Educar, Curitiba, Especial, p. 151170, 2006.

BARCA, Isabel. Ideias chaves para a educação histórica: uma busca de (inter) identidades. História Revista, Goiânia, v.17, n.1, p.37-35, jan/jul. 2012.

BARCA, Isabel. Educação histórica: vontades de mudanças. Educar em Revista, Curitiba, Brasil, n.42, p. 59-71, out/dez, 2011.

BARCA, Isabel. Educação histórica: pesquisar o terreno, favorecer a mudança. In: SCHMIDT, M. Auxiliadora; BARCA, Isabel. Aprender história: perspectiva da educação histórica. Rio Grande do Sul: Editora UNIJAÍ, 2009, p. 54-76.

BARCA, Isabel. Marcos de consciência histórica de jovens portugueses. Currículo sem Fronteiras, v.7, n.1, p. 115-126, jan/jul. 2007.

BARCA, Isabel. Educação Histórica: uma nova área de investigação. Revista da Faculdade de Letras. História. Porto, III Série, v. 2, p. 13-21, 2001.

CARRETERO, Mario. Documentos de identidades: a construção da memória histórica em um mundo globalizado. Tradutor: Carlos Henrique Lucas Lima. Porto Alegre: Artmed, 2010.

CERRI, Luis Fernando. Ensino de História e consciência histórica. Rio de Janeiro: Editora FGV, 2011. 
COOPER, Hilary. Aprendendo e ensinando sobre o passado a crianças de três a oito anos. Educar, Curitiba, Especial, p. 171-190, 2006.

FREITAS, Itamar. Aprender e ensinar história nos anos finais da escolarização básica Aracaju: Criação, 2014.

KOSELLECK, Reinhart. Futuro Passado: Contribuição à semântica dos tempos históricos. Tradução: Wilma Patrícia Maas, Carlos Almeida Pereira; revisão César Benjamin. Rio de Janeiro: Contraponto-Ed. PUC-Rio, 2006.

KOSELLECK, Reinhart. Uma história dos conceitos: problemas teóricos e práticos. Estudos Históricos, Rio de Janeiro, v.5, n.10, p. 134-146, 1992.

LEE, Peter. Por que aprender História? Educar em Revista, Curitiba, Brasil, n. 42, p. 19-42, out/dez. 2011.

LEE, Peter. Em direção a um conceito de literacia histórica. Educar, Curitiba, Especial, p. 131-150, 2006.

RÜSEN, Jörn; SCHMIDT Auxiliadora Maria; BARCA Isabel; MARTINS, Estevão de Rezende (Orgs.) Jörn Rüsen e o ensino de História. Curitiba: Editora UFPR, 2011.

SILVA, Cristiani Beretada. O Ensino de História - algumas reflexões do Reino Unido: entrevista com Peter J. Lee. Tempo e Argumento. Florianópolis, v. 3, n. 2, p. 216-250, jul/dez. 2012. 